\title{
AS PAISAGENS FANTÁSTICAS NUMA CIDADE AMAZÔNICA SOB O OLHAR DOS TAXISTAS
}

\section{Flávio Leonel Abreu da Silveira Pedro Paulo de Miranda Araújo Soares}

\section{$\mathrm{O}$ imaginário urbano belemense ${ }^{1}$}

O presente artigo é resultado de uma pesquisa realizada entre os anos de 2007 e 2008 . Nosso objetivo na época era captar as impressões e as interpretações de antigos taxistas sobre a cidade de Belém (PA) ao longo do tempo, de modo a refletir sobre as maneiras pelas quais os trabalhadores vivenciaram e sentiram as mudanças ocorridas na urbe, bem como o seu ponto de vista sobre este processo. Dessa forma, empenhamo-nos em coletar narrativas destes profissionais sobre o seu ofício, acerca das modificações ocorridas nos espaços da cidade, além das histórias fantasmagóricas ou escabrosas em que o personagem do taxista se insere como protagonista do evento narrado.

Ao longo da pesquisa de campo foram visitados, principalmente, dois pontos de táxi localizados

Artigo recebido em 09/09/2010

Aprovado em 23/03/2012 na avenida Presidente Vargas, uma via central da cidade de Belém que se caracteriza como um espaço de intensa circulação de pessoas oriundas de diferentes camadas sociais, representantes de múltiplas experiências no mundo urbano belemense, refletindo a heterogeneidade cultural (Velho, 1994) presente na metrópole. Um dos pontos pesquisados foi a Associação dos Taxistas da Praça da República, situada em frente ao Hilton, o primeiro hotel cinco estrelas a ser edificado na cidade.

O segundo ponto, mais próximo à área comercial da mesma avenida, encontra-se na esquina com a rua Manoel Barata, ao lado do extinto Cinema Palácio e do também extinto Central Hotel, cujo prédio, hoje reformado, comporta uma grande loja de vestuário. As conversas com os motoristas que labutam nesses locais nos conduziram por uma rede de interlocutores entre os quais estão seu Alain, presidente do Sindicato de Taxistas do Estado do Pará, e outros três taxistas aposentados que 
nos receberam em suas respectivas residências, seu Nascimento, seu Laranjeiras e seu Manoel.

No presente artigo focalizaremos prioritariamente as narrativas sobre assombrações ou "visagens", dando ênfase, assim, às paisagens fantásticas presentes no mundo urbano contemporâneo de uma capital situada na Amazônia. No entanto, essas histórias de caráter assustador não se encontram isoladas das demais que ouvimos durante a pesquisa, uma vez que compóem um mosaico de narrativas e imagens relativas à cidade de Belém. Tal mosaico revela as transformaçōes dos "lugares praticados" (Certeau, 1994) e a configuração de paisagens urbanas cujas auras são animadas por seres/entidades que vagam - especialmente - à noite, compondo uma parcela significativa do que poderíamos chamar de espírito do lugar.

As histórias sobre o contato com o sobrenatural estão geralmente vinculadas a episódios marcantes na vida dos motoristas, sendo identificadas também à dinâmica da trajetória urbana belemense em diferentes momentos da segunda metade do século XX. Nesse sentido, quando os taxistas narram as histórias, percebe-se que a "função fantástica da memória" (Rocha e Eckert, 2000) exerce o seu caráter flexível e elástico, vinculando novamente imagens (res)guardadas pelos narradores a experiências diversas, porque vivenciadas ao praticarem o espaço urbano a partir das deambulações que realizam em seus automóveis.

Valorizamos a experiência imaginativa e fabulatória do narrador quando tal personagem estabelece interações complexas com o Outro, mais especificamente com a plateia que o escuta. Portanto, seguindo as indicações de Kappferer (1986), entendemos a narrativa como um ato de performance que encerra tanto possibilidades para a constituição e o ordenamento da experiência, quanto para sua reflexão e comunicação. Pelo seu caráter reflexivo, a narrativa oferece condiçôes para os sujeitos - no mundo urbano, para o caso que nos interessa - significarem e acomodarem sua experiência temporal em relação à dinâmica espacial.

Ao contar uma história a outra pessoa, o narrador coopera na composição do acervo de narrativas e imagens do ouvinte, o qual sempre se constitui como um potencial narrador. $\mathrm{O}$ ouvinte repassa a história que escutou quando, em outra situação, o seu papel no jogo narrativo se inverte, encarnando a figura benjaminiana do narrador de histórias que está longe de desaparecer no mundo urbano. Portanto, as narrativas surgem na maioria das vezes em contextos de sociabilidade e de troca de experiências. Otávio (42 anos), taxista da Praça da República comentou o seguinte:

São relatos que são comentados entre os taxistas, sabe? Entre nós mesmo, eles comentaram. Quer dizer, é normal taxista comentar o que aconteceu, o que acontece... $\mathrm{Na}$ maioria das vezes, acontece coisas, e a gente: Pô, aconteceu uma coisa comigo! A gente conta...

Dessa maneira, estamos diante de uma forma social centrada em um ato de fala apresentando um forte caráter performático. Trata-se da ação de narrar como uma composição poético-imagética relacionada com a elaboração da tessitura de uma narrativa (Ricoeur, 1994). Ou ainda, o narrar constitui uma ação inteligente e sensível de erigir uma intriga narrativa capaz de revelar o evento assombroso que aproxima o narrador e a plateia a partir de uma performance envolvendo a própria poética da narrativa (e as imagens que suscita), da mesma forma que também inclui a entonação da voz e os gestos do performer na interação com os ouvintes. ${ }^{2}$

Ao contar tais histórias acerca de suas experiências com o assustador e, portanto, com o medo e suas paisagens, os interlocutores que participaram da pesquisa tendem a evocar as diversas formas de vivenciar o lugar, bem como de interagir com outros sujeitos no mundo urbano, onde as dimensões fantásticas e fabulatórias do vivido emergem com força, trazendo à tona as complexidades das imagens da paisagem metropolitana e o onirismo das “imagens dialéticas" (Benjamin, 1994) dispersas na experiência temporal da cidade e em suas transformaçôes modernizadoras desde pelo menos o boom da extração da borracha entre os séculos XIX e XX (Sarges, 2002). As narrativas sobre temas relativos às "visagens" mostram-se, desse modo, fundamentais para a compreensão dos processos transformativos pelos quais vêm passando a cidade de Belém, considerando-se o lugar da narrativa na vida social 
e na construção dos sentidos sobre o viver em uma urbe situada no norte do Brasil.

\section{Narrativas sobre "visagens"}

Para figurar neste artigo escolhemos as narrativas sobre o fantasmagórico, especialmente aquelas relacionadas com os espectros femininos, as quais possuem elementos constitutivos que nos permitem refletir sobre o tema da pesquisa, já que dizem respeito às transformações das paisagens que compõem o mundo urbano belemense a partir da ótica de profissionais - os taxistas - cujo ofício implica a relação intensa e direta com os diversos espaços que integram a urbe amazônica. Além disso, estamos preocupados com questôes metodológicas referentes ao trabalho de campo com os motoristas no contexto urbano, uma vez que é preciso também considerar o exercício de sua labuta. Por isso, juntamente às narrativas sobre "visagens" privilegiamos as questôes relativas ao deslocamento ${ }^{3}$ pelo espaço urbano e às mudanças na paisagem belemense que esses trabalhadores acompanharam ao longo do tempo.

Acreditamos que o contínuo deslocamento pelo espaço citadino engendra uma forma de conhecimento específica sobre o mundo urbano, um mapeamento (Gell, 1985; Ingold, 2000). Ou ainda, os deslocamentos estabelecem "formas sensíveis" (Sansot, 1986) de atuar na cidade e, por isso, de mapear cognitivamente os lugares e suas espacialidades, tema ao qual retomaremos adiante. Soma-se a isso o fato de que a contínua circulação pela cidade ao longo dos anos confere relevância ao olhar desses profissionais e ao caráter móvel e elástico de suas memórias (Rocha e Eckert, 2000), tornando-os capazes de identificar, mediante as suas constantes derivas nos espaços citadinos, as diferentes camadas temporais sobrepostas na paisagem belemense oriundas dos processos dinâmicos de modificação que a urbe experimenta.

Em uma entrevista realizada em um banco da Praça da República em frente ao ponto dos taxistas daquele local, seu Fabiano (aproximadamente 60 anos) narrou uma experiência pessoal em meados da década de 1970, na qual a imagem do desloca- mento emerge como um aspecto fundamental na construção do episódio narrado:

Pedro - Mas os taxistas tinham medo disso [as visagens], ou era...

Seu Fabiano - Não, era normal! [...] É, só uma vez, né... Que eu venho, peguei uma corrida pra [avenida] Perimetral, da Perimetral eu vim parar na Universidade [Federal do Pará], quando eu olho pelo retrovisor tinha uma freira no banco traseiro. Aí eu me arrupiei todinho! Quando eu dobrei na universidade, que eu saí da Perimetral, que eu peguei a Augusto Corrêa, que eu cheguei no claro, olhei e ela num tava mais... [risos]

$\mathrm{Na}$ fala deste senhor aparece, subliminarmente, a imagem da fronteira entre o rural e o urbano, pois certas regiōes limítrofes podem surgir dentro da própria cidade, uma vez que algumas áreas apresentam índices de urbanização e de modernização - no que se refere a sua infraestrutura e equipamentos urbanos, às visões de mundo e às práticas cotidianas de seus habitantes - que diferem, por exemplo, das áreas periféricas mais afastadas do centro da cidade. Tais imagens, de alguma forma, indicam aquelas relativas às "regiōes morais" (Park, 1987).

A própria denominação da avenida, isto é, "Perimetral", parece trazer consigo a concepção de um espaço de fronteira, de demarcação de áreas distintas no corpo da cidade, especialmente em relação ao centro de Belém. Trata-se de uma longa avenida situada praticamente às margens do rio Guamá e que contorna bairros periféricos como o Guamá e a Terra Firme, consideradas nos termos locais como "baixadas". 4

Nota-se, retomando a narrativa de nosso interlocutor, que ao primeiro sinal de claridade, a presença da iluminação pública, a freira desapareceu. Tudo indica que a "visagem" estava vinculada a outro tipo de paisagem noturna - e a um local ermo e pouco conhecido - ou melhor, ao lusco-fusco ligado ao contexto das sombras e às indefinições visuais que apontam para as imagens poderosas do "sinistro", das "marcas terrificantes" e do "caos" (Durand, 1989). 
Caso semelhante ao de seu Fabiano é o que aparece na história narrada por seu Nascimento (72 anos), um motorista de táxi aposentado que nos recebeu em sua residência. Sentado confortavelmente em uma poltrona na sala de estar, ele nos contou:

E eu trabalhei 10 anos em ônibus, 10 anos em ônibus, aí... Vamo meter uma assombração por aí! Eu trabalhava numa linha chamada Circular... Circular. Essa Circular tinha uma pessoa, era uma mulher no ônibus de meia-noite. Tá, saindo? Tá, tá gravando? [questiona seu Nascimento] Ela pegava o ônibus meia-noite na Conselheiro Furtado, esquina com a Serzedelo [Corrêa]. Aonde tem uma farmácia hoje, Big Ben. Ela apanhava meia-noite. [...] Ela pegava o ônibus no canto da Gentil [Bittencourt]! E nós entrávamos na Conselheiro. Quando chegava em frente ao presídio São José, ela sumia! Então muitos companheiros tinha medo de "fazer o Cristo". 5 Então, quem "fazia o Cristo" àquela altura? Era eu, era o Jaime e era o Barrasco. A gente recebia quinze cruzeiros pra "fazer o Cristo", que os medrosos, que eles tinham medo! E dava medo mesmo! Porque a mulher fazia sinal, a gente tudo aceso, o, a luz do ônibus, ela fazia sinal, a gente parava, ela entrava pela porta traseira e sentava no banco do ônibus. Em frente ao presídio ela sumia!

O taxista, na época motorista de ônibus, revela em sua narrativa a presença de uma assombração que surgia misteriosamente à meia-noite e entrava no ônibus que ele dirigia. A imagem assustadora de alguma forma tensiona signos ligados ao moderno e à tradição, pois apesar do símbolo de modernidade presente no episódio - o ônibus percorrendo a cidade - a narrativa aponta para imagens vinculadas a uma dimensão "folclórica" do medo, como indica Gilbert Durand (1989, p. 66), ao afirmar que a "hora do fim do dia, ou a meia-noite sinistra, deixa numerosas marcas terrificantes: é a hora em que os animais maléficos e os monstros infernais se apoderam dos corpos e das almas", assim como as almas penadas que circulam tenebrosas pelas ruas. Se "a noite é concedida aos defuntos" como aparece na obra de Schmitt (1999, p. 198) é porque os "homens despertos", a partir de horários aziagos (para o caso belemense as $18 \mathrm{hs}$ e às $24 \mathrm{hs}$ ) são capazes de vislumbrar a "visagem" da mulher como uma das dimensões fantasmagóricas das paisagens fantásticas. Portanto, tais imagens estão ligadas à experiência do medo (Delumeau, 1996) - uma "paisagem do medo", de acordo com Tuan (2006) - e, por isso, relacionada com um evento emocionalmente desestabilizador, pois as pessoas experimentam sensações de terror e angústia diante do desconhecido e do misterioso ao se depararem com o assombro.

Nota-se que a imagem terrificante da mulher percorre certa geografia do terror, uma "geografia fantástica" nos termos de Durand (1989), ou mesmo uma "geografia imaginária" para Maffesoli (1994). A mulher embarca no transporte coletivo exatamente no "canto da Gentil", em uma das esquinas do quarteirão onde está situado o antigo e arruinado cemitério da Soledade, desembarcando posteriormente nas proximidades do então presídio São José, um cenário de violência e insalubridade que perdurou em Belém até o final dos anos de 1990 e que, durante os séculos XVIII e XIX, estava vinculado a enforcamentos de pessoas que cometeram delitos (Cruz, 1973, p.18). Trata-se de um lugar onde até hoje se acredita que apareçam "visagens". ${ }^{6}$ Gilbert Durand (1989, p. 77) faz referência às "deusas funerárias" dos Germanos - "para quem o sistema ritual de morte é o enforcamento" - que chamam os mortos com uma corda. $\mathrm{Na}$ narrativa de seu Nascimento não há referência à corda, mas a presença do espectro feminino em um local onde ocorriam enforcamentos no passado aproxima, de alguma forma, tais imagens terrificantes.

É preciso destacar, ainda, que o referido presídio quando construído situava-se em uma região limítrofe do perímetro urbano de Belém com as áreas florestadas da região, enquanto hoje, devido às dinâmicas urbanas e às transformações da configuração espacial da cidade, encontra-se em uma região de Belém considerada central. Logo, a visagem traz à tona este contraste próprio à trajetória urbana complexa e às temporalidades acidentadas de cidades brasileiras (Rocha, 1994), como é o caso de Belém. 
O que nos parece claro é que no espaço citadino as fronteiras assumem diversas formas simbólicas, socioeconômicas, geopolíticas -, definindo, assim, um olhar lançado aos lugares por parte dos motoristas que percebem e captam as diferenças presentes no mundo urbano belemense por meio de suas "viagens dentro da metrópole", que para Canclini (1997, p. 109) nos auxiliam a "explorar a constituição do imaginário urbano", uma vez que a cidade se constituiria para o viajante como um conjunto fragmentário de imagens dos lugares por onde passa em seu cotidiano. Estamos, portanto, no âmbito do sensível da vida social (Sansot, 1986) relacionado com os "espaços praticados" (Certeau, 1994) e vividos por diversos atores sociais. Se a alguns locais estão aderidas imagens ligadas ao universo fantasmático, isso nos leva a indicar que os taxistas identificam estas áreas como espaços distintos que compõem a cidade e cujas paisagens detêm elementos sensíveis que diversificam suas auras.

No relato de seu Fabiano o que vem à tona como imagem da fronteira é a presença de um espaço de urbanização insipiente, enquanto na narrativa de seu Nascimento é observada a imagem obscura e misteriosa dos arredores de um local de encarceramento que inspira temor e que possui seu duplo na imagem sombria da mulher-fantasma. Em cada caso, as narrativas exprimem um contraste entre paisagens que se distinguem entre si, configurando dimensões auráticas diversas no corpo da urbe.

$\mathrm{Na}$ narrativa de seu Luís, um dos profissionais do ponto de táxi localizado na avenida Presidente Vargas em esquina com a rua Manoel Barata, esse contraste relativo aos limites colocados pela imagem da fronteira no interior da cidade aparece de outra maneira. Naquele dia, em plena calçada, em meio aos pedestres que passavam apressados formou-se uma roda de conversa composta não apenas pelos taxistas e os pesquisadores, mas também por vendedores de jornais, guloseimas e habitués daquele cenário. Quando obteve a atenção de todos para si, seu Luís contou:

Não, mas era verdade, tinha visagem mesmo! Tinha uma, tinha uma loura aqui que era filha do, da... do dono da antiga Rádio Liberal, foi prefeito, filha do Lopo de Castro. Ela pegava táxi ali pro, ali praquela área do cemitério à noite. Aí vinha, ela fazia sinal e ela dizia: "Me leve em tal canto!" Na casa... Geralmente na casa dela que era aqui na Cidade Velha. ${ }^{7}$

Quando chegava lá, por exemplo: o cara que, que me contou que levou ela ali, ele levou, chegou lá e ela disse: "Olha, eu não tenho dinheiro aqui, dá pra você vir receber de manhã? Eu vou morar aqui [no sentido de "eu moro aqui"], tu vai ver, eu vou entrar". E ele: “Tudo bem." Ela entrou. Ele foi embora... De manhã quando ele chegou lá umas 10 horas, bateu, veio a senhora que era a dona da... Mãe dela. Aí ele falou:

- Olha, eu vim receber o dinheiro de uma corrida.

Aí, ela falou:

- Uma corrida...?

- Foi! Eu trouxe uma moça ontem.

Aí, ela apontou pro quadro:

- É aquela moça ali?

Aí ele disse:

- É, é essa mesmo, senhora!

Aí ela pegou e disse:

- Olhe, onde que você encontrar essa moça, o senhor pode trazer pra cá! Quanto foi a corri$\mathrm{da}$ ?

- Foi "tanto".

- Ela é minha filha, ela já morreu e tal...

Aí ele não quis o dinheiro: "Não, não, não quero o dinheiro!".

Mas agora, é verídico! Verdade mesmo! Muitos, muitos casos tinham naquela época!

Novamente a imagem da mulher emerge do breu da noite nas proximidades de um cemitério, indicando "ressonâncias fantásticas" relativas à "epifania da morte" (Durand, 1989, p. 69). A anima macabra espera, paciente, ser levada à morada em que viveu outrora, localizada no bairro da Cidade Velha segundo seu Luís. A imagem fantástica da mulher cuja alma deambula pela noite nas proximidades do cemitério - "um albergue de fantasmas", para usarmos uma imagem bachelardiana (Bachelard, 2006) - vibra como potência terrificante. O 
espectro feminino, ao constituir a aura de uma paisagem fantástica no contexto citadino, nutre com seu dinamismo imagético a "função fabulatória" (Caillois, 1938) daqueles que experienciam o mundo urbano belemense e o narram.

Nestes termos, o bairro Cidade Velha aparece no cenário citadino e nos "jogos da memória” (Rocha e Eckert, 2000) como um lugar de fronteira, cuja singularidade está vinculada a uma paisagem de outrora indicadora das açóes humanas no passado colonial, uma vez que, de acordo com os desígnios de uma coletividade e o momento histórico em consonância com a "economia emocional" (Crapanzano, 1994), determina-se o que é importante para lembrar, bem como de que maneira deve ser lembrado. As ruas estreitas e até hoje pouco iluminadas - resguardando certa calma - juntamente com a arquitetura colonial criam um contraste em relação ao restante da cidade - moderna, ruidosa e agitada -, produzindo a impressão de ancestralidade bastante propícia à evocação das imagens do fantasmagórico, como indica a obra do literato paraense Dalcídio Jurandir, editada em 1960 e intitulada Belém do Grão-Pará.

Em uma passagem deste livro - que tem sua ação transcorrida no início da década de 1920 -, as crianças Libânia e Alfredo caminham pela cidade de Belém. Ao se aproximarem das antigas construções da Cidade Velha, admiram a Igreja de Santo Alexandre. Nesse momento Libânia conta: "Aqui nesta Igreja está encantada uma menina”. E logo mais, complementa: "Aqui nesta Igreja encantou-se uma menina, seca-seca [sic!], por ter levantado uma vassoura contra a mãe dela" (Jurandir, [1960] 2004, pp. 132-133). A menina, então, aponta para o conjunto arquitetônico constituído pela igreja e o Colégio do Carmo, dizendo que "no Carmo havia também muito encantamento. Uma freira aparecia na janela" (Idem, p. 133). Novamente as imagens de espectros femininos vibram no cenário fantástico evocadas pela narrativa da personagem. Ambas estão aderidas à espacialidade das edificações coloniais, persistindo no tempo e animando o "imaginário urbano" (Certeau, 1995).

Segundo Cancela (2009), a Cidade Velha no início do século XX passou a ser vista como espaço sombrio, pantanoso e insalubre. Tratava-se de uma ambiência antagônica ao ideal haussmaniano de urbanização e higienização das cidades europeias que é exaltado nesse período. As famílias abastadas - os fazendeiros da Ilha do Marajó e os senhores da borracha ${ }^{8}$ - mudam-se do "bairro da Cidade", considerada a primeira aglomeração urbana de Belém, em direção a um novo espaço de representação de status social, a chamada Estrada de Nazaré. Somente a partir daí o "bairro da Cidade" passa a ser denominado de "Cidade Velha".

Dessa forma, na topografia simbólica da cidade apreendida por Libânia, infere-se nada ser mais natural do que a Cidade Velha aparecer como espaço fantástico onde persistem fantasmas e encantamentos, bem como os assombros utilizados como forma de controlar e educar as crianças pelos mais velhos - a menina encantada na igreja fica "seca-seca” e em outras narrativas vira pedra ao tentar agredir a mãe com uma vassoura. Ali também são representados os fantasmas de uma Belém colonial que, naquele momento, passava a ser esquecida, tornando-se signo do decaimento e, portanto, "espaço melancólico de ruínas" (Trigg, 2010).

Tudo indica que as idiossincrasias e as imagens relativas às temporalidades diversas se misturam e se confundem ao sabor das formas de viver numa cidade como Belém, revelando a partir de suas camadas e meandros as tensôes presentes nas vicissitudes espaço-temporais que a cidade experimenta, dadas as formas pelas quais seu corpo é modificado mediante as ações humanas. Portanto, a ação criadora de transformá-la está em paralelo ao ato imaginativo de fabular acerca de sua existência como construto dinâmico e vivo, onde as mulheres fantasmagóricas que emergem nas paisagens fantásticas belemenses revelam os tempos plurais que vibram e duram, indicando as mudanças experienciadas pelos sujeitos que vivem e praticam o espaço citadino em seu devir temporal acidentado.

As histórias sobre visagens aparecem aqui geralmente associadas aos tempos pretéritos - ou ain$\mathrm{da}$, às paisagens de outrora - e a outras dinâmicas da vida social presentes no contexto belemense, à luz do presente vivido pelos narradores. No entanto, percebemos a existência de narrativas como a de Otávio (42 anos), na época o presidente da Associação dos Taxistas da Praça da República, que 
indicam a existência de apariçôes "visagentas" na atualidade. De acordo com Otávio:

Tem um colégio de freiras na BR, então ele pegou essa freira na $B R$, ele pegou uma... uma mulher toda de branco e ela mandou justamente pra, não sei se é Pio XII ou Pio X, é uma, é uma, é um colégio de freira que tem na BR antes de chegar na Massafra [loja de materiais de construção], por ali. Ele pegou e ela disse:

- Olha, você me deixe nesse endereço.

E ela lá... tá. Então ela disse que, aí, ela falou o valor, o preço, tudinho.

- Agora me aguarde aí? Vou buscar o dinheiro aqui dentro.

Aí ela foi e ele esperando lá... Aí ele viu que ela tava demorando e ele bateu, aí veio outra freira falou com ele, ele falou:

- Não, tem uma senhora que entrou aí, ela pegou meu táxi, entrou e disse que ia pegar dinheiro e até agora eu tô esperando e nada...

Aí a freira observou, foi lá dentro. Quando voltou, trouxe a foto da, da... Foi essa pessoa, foi essa pessoa? Porque têm tantas aí, foi essa pessoa?

- Foi, foi essa senhora...

- Olha, lamento te dizer, mas essa pessoa já morreu!

$\mathrm{O}$ velho ficou meio...

- Mas como ela morreu?

- Não, ela morreu atropelada aqui, foi bem perto, ela vinha pra cá e morreu atropelada.

Mas a freira pagou! [risos]

Mas, recentemente isso? [Pedro]

Recente, recentemente. Quem foi que me disse rapaz? Não me lembro quem foi que me disse, não me lembro. Essa freira foi recente! Ela morreu, parece que tinha morrido há uns três anos atrás, dois anos atrás. Atropelada na BR.

Notamos que a narrativa em questão segue a mesma estrutura que as demais, lembrando aquelas que envolvem a figura tenebrosa da "moça do táxi" que se passa na primeira metade do século XX, como aparece em publicaçôes sobre as "visagens" presentes no mundo urbano de Belém, a exemplo do trabalho de Monteiro (2005). Assim como nar- rou seu Luís, Otávio traz à tona uma história na qual o taxista descobre que transportara uma pessoa já falecida quando, posteriormente, se dirige ao local indicado para cobrar pelos serviços prestados.

No entanto, a diferença entre as narrativas reside no fato de que os contextos nas quais ocorreram são distintos. A ação narrada por Otávio acontece na rodovia federal BR 316, situada na região metropolitana de Belém. Tal espaço de deslocamento ressalta o papel das estradas como uma espécie de "não lugar" (Augé, 1994), o que neste caso representa um local de anonimato e solidão, no qual o motorista se encontra à deriva enquanto não alcança seu destino. Este "não lugar" seria propício a apariçôes sobrenaturais, desde que o consideremos um espaço relacionado com o sofrimento e o terror, onde muitas vidas já tiveram fim. Princípio semelhante orienta os temores sobre rios, mares, oceanos e mesmo as praias (Corbin, 1989), paisagens nas quais as aparições de espectros e de fantasmas pertencentes às pessoas falecidas em naufrágios ou devoradas por bestas marinhas também são recorrentes. Porém, se sobre a potência turbulenta das águas misteriosas são temidas as forças inclementes da natureza e os desígnios de divindades aquáticas, nas rodovias essa expressão da modernidade e do deslocamento calculado - são temidos os próprios sujeitos e suas obras, como o condutor incauto ou sob efeito de álcool, as máquinas descontroladas e as estradas traiçoeiras com suas curvas sinuosas. Daí não serem estranhas as manifestações de "visagens" na forma de um objeto tecnológico específico, tão caro à modernidade e àqueles que se deslocam, como é o caso do automóvel. A respeito disso, seu Nascimento contou:

Eu acho que hoje ainda aparece, ainda! Você indo pra Vigia à noite, na primeira curva que você vai encontrar na Vigia, que nós sabemos, de um chofer para o outro, você dá sinal de luz aqui e o outro responde lá, né. Quer dizer, o que vai aqui dá sinal de luz que vai aqui, o outro dá sinal de luz que vem de lá pra cá. E você nunca cruza esse carro. Ele, tu dá sinal, ele responde, "prá, prá, prá, prá", mas você num passa por ele. E isso já é velho! 


\section{Imaginários em torno da cidade narrada}

A etnografia no mundo urbano de Belém, considerando a importância do tema relativo à mobilidade e ao deslocamento de seus habitantes pelos espaços públicos, evoca as imagens relacionadas com as "travessias pela cidade" - a pé, em automóveis ou coletivos (Canclini, 1997; Caiafa, 2007). Tais imagens, seguindo a inspiração de Durand (1989), constituem um rico acervo que revela a força e a persistência do imaginário que pulsa na cidade, indicando os processos de assimilação acomodadora ao meio urbano pelos citadinos aos quais se relacionam tanto o caráter subjetivo quanto a dimensão física de "praticar" os lugares de pertença a urbe e de exercer agência sobre ele. Nestes termos, refletir sobre os vínculos simbólico-afetivos de seus habitantes é seguir as indicações de Canclini (1997, p. 109), quando o autor sugere que é necessário "pensar a cidade tanto como lugar para habitar como para ser imaginado".

Portanto, a "constituição imaginária" (Gravano, 2005) da cidade efetiva-se na movência das imagens e das metáforas que alegorizam a urbe real. A cidade, de acordo com Gravano, "é a construção de uma imagem incessantemente reconstruída", figurando "'como lugar do acontecimento cultural e como cenário de um efeito imaginário'; 'o urbano de uma cidade se constrói”" (Silva apud Gravano, 2005, p. 29). A cidade, dessa forma, é vivida e imaginada na medida em que é rememorada como o lugar de pertencimento pelas pessoas que a praticam. É então que as camadas de memórias que compõem a experiência coletiva na urbe se adensam ou diluem em certos locais, vibram e esmaecem diante da potência das imagens e dos espaços de celebração da vida (Maffesoli, 1994) ordinária com suas temporalidades múltiplas articuladas aos espaços citadinos.

A perspectiva de Eckert e Rocha acerca da dinâmica do mundo urbano contemporâneo, considerando os itinerários de seus habitantes, a partir de uma etnografia da duração "aceita como suposto que a matéria das lembranças ou reminiscências de um tempo vivido adquire uma substância somente se ela se 'temporaliza' sob a forma de ondulaçōes do próprio ato que encerra o tempo pensado" (2005, p. 153). Sendo assim, a importância do imaginário e da narrativa emerge com força para a compreensão da urbe amazônica como aparecimento de uma civilização nos trópicos.

Para a reflexão que nos propomos neste artigo, partimos do princípio de que as narrativas sobre o passado de Belém já constituem a própria expressão do ponto de vista desses motoristas sobre a experiência temporal da cidade. Elas revelam as aspiraçôes, os desejos, os devaneios, em suma, os imaginários sobre a cidade. Portanto, os pontos de vista aqui expressos são tanto do taxista, como do antigo morador da cidade. O diálogo com o motorista aposentado seu Manoel (64 anos) auxilia a compreensão dos processos de transformação das paisagens da urbe a partir de uma perspectiva bastante particular que se deve à profissão que este senhor exercia. Como segue: ${ }^{9}$

Seu Manoel, responda uma coisa, quando o senhor começou a trabalhar, como era a trafegabilidade das ruas?

Péssima! Só o miolozinho da capital é que era bem trafegável. E segundo o meu irmão, a maioria não prestava. Atoleiros, lama, os pneus do carro só andavam sujos, o carro só andava com os baixo enlameado, todo dia você tinha mesmo por obrigação lavar o carro: péssimo, péssimo mesmo! Hoje não, hoje a cidade em comparação com aquele tempo ta muito bem saneada. Pra você ter uma ideia, essa Duque de Caxias era um lamaçal inteiro. Marquês de Herval tinha lugares que você nem podia entrar. E por Antonio Everdoza nem se fala! ${ }^{10}$ [risos]

Antonio Everdoza é atrás da Pedro Miranda, né? Atrás da Pedro Miranda. A Pedro Miranda prali da Lomas [Valentina] pra sair na Dr. Freitas, ali passou foi anos sem nem passar carro ali. Ali onde hoje tá o Sambódromo, aquele negócio ali, né, o carro desaparecia ali dentro do aningal [risos]. Era difícil, viu Pedro, era difícil. Tinha o seu lado bom, tinha o seu lado bom que eu acabei de transmitir, que era o custo de vida, o dinheiro circulante que era muito melhor do que hoje, que estava ao alcance da camada menor e dava o direito de andar de táxi, né, mas em compensação tinha esse outro lado negativo. 
As palavras de seu Manoel apresentam parte do traçado e da fisionomia das ruas de Belém, evocando imagens sobre a cidade que situam o ouvinte - aquele familiarizado com a planta da cidade espacialmente em seu interior, mas que ao mesmo tempo possuem forte densidade temporal, trazendo à tona o engajamento do senhor àquele meio, na medida em que aparecem dados de sua percepção sobre o espaço narrado - a lama respingando sobre a pintura do carro, a dificuldade em mover o automóvel, os caminhos a serem percorridos. Com base em narrativas como essa, é possível refletir sobre a questão do mapa mental, conceito que revela abordagens heterogêneas e que indica a presença de um campo interdisciplinar bastante complexo, envolvendo disciplinas como biologia, psicologia, geografia, antropologia e sociologia, entre outras. Aqui nos interessa pensar o mapa mental seguindo as indicaçôes de Gell (1985, pp. 272-273), que o associa à ideia de navegação, ou ainda, a "alguns esquemas inferenciais utilizados na conversão de informação em decisōes e ações práticas" e à practical mastery theory, quando o autor aponta a perspectiva de Pierre Bourdieu, o qual afirma estar a maestria de um espaço ambiental ligada a familiaridade com a prática em oposição ao espaço cartesiano.

Quanto aos espaços conhecidos e reapresentados pelos taxistas em suas narrativas, é preciso levar em conta que o espaço narrado se revela como um "espaço fantástico" (Eckert e Rocha, 2005), pois as imagens da cidade evocadas permanecem na memória de nossos interlocutores na forma de referências e suportes imaginários que contribuem na elaboração e constituição de "mapas mentais" (Gell, 1985). Sendo paisagens mnemônicas, não existem em seu suporte físico como se apresentam em suas falas devido às transformações que a cidade sofreu ao longo do tempo. Portanto, trata-se de uma paisagem de outrora. Nesse sentido, evocamos as palavras de seu Nascimento (72 anos) sobre a cidade de Belém:

Olha, a cidade é essa que tu tá vendo aí. A cidade de Belém era essa que está aí. Só que não era asfaltado. Era chão. Era chão... Eu me lembro que uma bela noite, num sei por que, eu peguei a Generalissimo, e, e, a Generalíssimo era paralelepípo e o trilho do bonde. E eu fui até A, a, a Conselheiro Furtado e entrei, a Conselheiro não era asfaltada, era chão. $E$ as ruas de Belém eram todas do quê? Paralelepipo, ou então piçarra, piçarra, terra. Hoje não, hoje tá asfaltada aqui a baixa da 14 que não entrava carro ali. Hoje tá asfaltado a baixa da Diogo Moia, que não passava carro, hoje você corre $100 \mathrm{~km}$ já sai na Doca, quer dizer, hoje tá tudo asfaltado. E que não era antigamente. Era só... lixo na rua, buraco, que não passava com o, quebrava o carro. Hoje não, a cidade de Belém mudou muito. Então, o que eu posso te dizer da minha história é essa...

As imagens evocadas por seu Manoel remetem, seguindo a expressão de Bachelard (1991), à matéria mole representada pela lama e mesmo pela vegetação que se encontrava à frente dos motoristas quando trefegavam pelas ruas; o narrador aponta para a inexorabilidade e a dureza do chão, da piçarra e das crateras que poderiam danificar um automóvel. Movimentar-se pela cidade implicava o conhecimento dos trajetos mais adequados e seguros, o que para Ingold (2000, p. 237) distancia este viajante daquele que, amparado por um mapa cartográfico, procura apenas determinar sua localização geográfica. Dessa forma a operação cognitiva fundamental para os taxistas não consistiria em saber "onde estou", mas sim "por qual caminho seguir", memorizando fluxos no tempo e não imagens estáticas no espaço.

Sentado na varanda de sua casa localizada no bairro da Pedreira, bairro em que mora há mais de trinta anos, o taxista aposentado seu Laranjeiras (83 anos) nos falou sobre a cidade em que viveu, evidenciando as operações cognitivas necessárias a um mapeamento do lugar. Quando perguntado sobre como era Belém quando começou a trabalhar "na praça", ele respondeu: ${ }^{11}$

Seu Laranjeiras - As, as ruas, ah, não tinha rua... a, as ruas que eram asfaltada era, as únicas ruas asfaltada em Belém até mil novecentos e... até mil novecentos e sessenta e quatro, sessenta e cinco era a Brás de Aguiar, a Brás de Aguiar e a Rodovia Sinap, que ia do Telégrafo 
para o aeroporto. Elas eram as únicas ruas asfaltadas em Belém. O resto de Belém, as ruas que eram calçadas, era com paralelepípedo. Você não conheceu o paralelepípedo?

Pedro - Em alguns lugares ainda tem... na Cidade Velha...

S. L. - É, é, pois é, era aquilo. E Almirante Barroso, que nos anos 50 ela foi encimentada, uma pista era encimentada de São Brás até na Bandeira Branca, ${ }^{12}$ ou seja, na Dr. Freitas adonde tem aquele viaduto. Até ali era encimentado. $\mathrm{O}$ resto era rua toda sem asfalto, cheia de buracos, não é como tá hoje. Hoje tá muito bonita Belém, ficou mais asfaltada, tudo asfaltado. Dantes num tinha isso. As ruas que davam mais condiçōes pra você andar era $G e$ neralíssimo, Avenida Nazaré, né, a São Jerônimo, a Gentil, a Brás de Aguiar que pegava ali na Serzedêlo, vinha até a Generalissimo; a, a Rua do Jurunas, que era lá no Jurunas; a Conselheiro Furtado que começava lá no Comércio e vinha até em Nazaré, vinha ali a Conselheiro; a Gentil começava lá na Serzedêlo e vinha até aqui a, aqui São Brás, perto de São Brás e as outras ruas, a Boaventura era rua muito acidentada... A Boaventura, a Diogo Moia, eram ruas que terminava aqui na Alcindo Cacela, terminava lá, porque pra frente era tudo era igapó.

A Alcindo Cacela ela vinha, da, da... da Unama, ${ }^{13}$ né? E ia até o Bar da Condor lá na Condor, na Cremação, né, a rua. Uma outra rua que começava lá na, no Ver-o-Pêso ${ }^{14}$ e ia até o outro lado da cidade, terminava também, começava dentro d'água e terminava dentro d'água, era a Padre Eutíquio. Era essas ruas, mas num era umas rua que dava pra você andar de carro, era só mesmo pelo centro e essas ruas que eu falei, que eram ruas que vinham daqui pro Marco, vinha pra São Brás... A Generalíssimo começava lá na, perto do Presídio, aí você pegava a Conselheiro, vinha, pegava a Generalíssimo já aqui em Nazaré. Começava ali e terminava aqui perto da Santa Casa, em Santa Luzia. É, a Avenida Nazaré também começava na Presidente Vargas, [que] começava lá no Cais do Porto, a Presidente Vargas, aí vinha, subia, pegava a Avenida Nazaré que começa- va na Serzedêlo e vinha até São Brás... aí a, a Avenida Nazaré. A outra é a São Jerônimo também que vinha e dava acesso até São Brás; e a Gentil. Essas três ruas vinha lá do comércio, da Praça da República até São Brás, terminava em São Brás. Em São Brás começava a Almirante Barroso, que era na época, era a Tito Franco. Há uns 40 anos eu me lembro que foi trocado o nome pra Almirante Barroso.

As outras são ruas que vinham pra Pedreira, pegavam ali a, a, pegava ali a Alcindo Cacela e vinham pra cá pra Pedreira pegar a Pedro Miranda ali adonde é a Unama. A outra é a Bernal do Couto que vinha, pegava a Pedro Miranda ali perto da Unama. E as rua aqui, era Mauriti que saía da Pedro Miranda, que e se unia à Lomas, né. Agora vai embora, vai até na, lá na Aldeia Cabana, ${ }^{15}$ né. Dantes num tinha aquilo. Aquilo tudo ali era igapó que ninguém andava, andava de pés, nem de bicicleta dava, andava, era muito acidentado ali. A Lomas era outra rua que dava acesso lá pra Almirante Barroso. Ia por aqui pela Pedreira e ia pra Almirante Barroso. Tinha a $1^{\circ}$ de Dezembro também, mas a $1^{\circ}$ de Dezembro não era trafegável. Tinha casas, mas só dava pra andar de bicicleta ou então de pés. E o bairro do Telégrafo era que tinha mais ruas. A Ferreira Pena que começava aqui perto da Unama, aí ia até a Curuçá, aí pegava a Curuçá e ia pro Telégrafo. Aí eu morei no Telégrafo na rua José Pio com a Curuçá. Agora, eu morei uns dois anos lá. Aí mudei e vim pra cá pra Humaitá nos anos 70... [...]

É, tirando disso, tinha a boate, tinha a Mosa. A Mosa era aqui na, na Alcindo Cacela, tinha o Chapéu Chinês e a Mosa era aqui na Vileta, uma casa grande que tinha lá, ainda tem essa casa bem na esquina da Vileta com a Almirante Barroso. Era uma casa bonita, um bangalô bonito, era uma boate. Só funcionava de 10 horas da noite pra frente e ia até de madrugada... Também não ia qualquer um lá, só ia pessoas de direito, né, pessoas, advogado, engenheiro, médico, pessoas que num eram formado, mas que tinham poder aquisitivo bom, né, é que iam lá. Não ia qualquer um não [risos]. Era considerado longe, né... É, era, era longe, só 
ia de táxi. Aí, o táxi ia levar. [...] Era adonde os homem, rapaz, rapaz solteiro, homem solteiro iam pra se divertir, é ali. Muito... Muitas mulheres moravam lá, tinha mulher, é, muito bonita e... é, eu podia contar uma história pra você, mas pode na entrevista [risos] você botar pra alguém escutar...

A narrativa de seu Laranjeiras indica, pelo menos até o ano de 1964, a existência de apenas duas ruas asfaltadas em Belém: a avenida Braz de Aguiar e a rodovia Sinap (esta última corresponde ao trecho da rodovia Arthur Bernardes que liga o bairro do Telégrafo ao Aeroporto de Val de Cãs). Partindo desta assertiva, a memória desse senhor percorreu diversas ruas, tendo sempre como referência o material utilizado na sua construção, o paralelepípedo, bem como as reminiscências de outra concepção de urbanidade, quando os trilhos dos bondes representavam um signo importante da modernidade amazônica. As imagens evocadas pelos três taxistas aposentados são construídas em íntima relação com sua profissão, pois eles examinam as ruas da Belém de outrora conforme a sua trafegabilidade por automóvel. Seu Laranjeiras, por exemplo, leva em conta a existência de locais como bares e boates - alguns só acessíveis de táxi - que representavam, durante a noite, fonte de sustento para o taxista.

As reflexões críticas de Ingold (2000) sobre a discussão em torno do tema dos "mapas mentais" - também abordado por Gell (1985) - deslocam a questão para um campo mais amplo, na medida em que o autor (re)pensa esta problemática não tanto pelo mapa bidimensional, mas pela ótica do mapeamento. Para Ingold, o processo de mapeamento está vinculado ao que o autor chama de wayfinding, isto é, a busca por caminhos associando deslocamento e percepção. Por isso, os mapeamentos dos lugares praticados sempre relacionam: (1) engajamento ao meio, neste caso a cidade, (2) memorização, ou seja, a criação de referências espaciais relativas a um acervo de imagens que auxiliam no deslocamento e (3) memória, no sentido de que o ato de mapear, imaginar ou inscrever um itinerário por uma região é, de certo modo, reviver a história do deslocamento que deu origem a esse mapa cognitivo.
Ingold sugere que os mapas cognitivos de sujeitos que se movimentam por uma região não são construídos na mente da mesma forma que Alfred Gell (1985) propôs. Gell, ancorado em suas pesquisas sobre navegadores micronésios, afirma que se trata dos mapas mentais constituídos como mapas cartográficos, nos quais a veracidade dos dados dispostos independe da localização do leitor em relação ao seu destino. Ao diferenciar navigation de wayfinding, Ingold (2000, p. 236) discute a possibilidade de pensar os mapas mentais não sob a forma de dados invariáveis inscritos na mente, mas como perspectiva que revela fluxos dentro da matriz de movimento constitutiva de uma regiāo. Sendo assim, o viajante urbano possui condições de saber exatamente onde está, apesar de não ter ideia de sua localização geográfica.

Nas narrativas apresentadas, estes dois conceitos de mapa - o panóptico e o perspectivo -complementam-se, pois em um primeiro momento existe apenas um mapa que segue o desenho da planta urbana de Belém. Como fez principalmente seu Laranjeiras, os interlocutores narraram o traçado das ruas, agrupando-as em bairros ou entre transversais e paralelas, imaginando as relações entre elas e sua sequência no corpo da cidade. No entanto, em um segundo momento esse mapa ganha perspectiva quando os taxistas assumem o ponto de vista que lhes é devido: o de alguém que transita diariamente pelas ruas da cidade. O mapa então deixa de lado os traçados das ruas e o desenho panóptico da cidade para ganhar vida no chão: agora são importantes os caminhos a serem seguidos, os buracos e crateras nas ruas, as condições de trafegabilidade, o mato, a lama e os pântanos, todos estes elementos que revelam a perspectiva do motorista. Trata-se de um ponto de vista específico, manifestando-se na confluência das lembranças de seu deslocamento na cidade com as paisagens mapeadas ao longo de suas travessias pela urbe amazônica.

Se no passado estes mapas auxiliavam os motoristas de Belém no seu deslocamento por uma cidade que não era completamente urbanizada - e ainda está longe de sê-lo - e detentora de um terreno bastante acidentado do ponto de vista geográfico, hoje tais paisagens figuram como a expressão de um viver e de um labutar na cidade que fazem re- 
ferência a determinado momento de sua existência, tratando-se de uma experiência sensível de "recuperação da memória urbana trazida pelas imagens" (Pesavento, 2002, p. 17). Aqui, as representações e as categorias de entendimento acerca do mundo urbano, ancoradas nas percepçóes de espaço e de tempo, contribuem para pensarmos as relações dos habitantes da urbe com as modificações das paisagens praticadas a partir do mapeamento dos lugares. Dessa forma, vinculamos nossa abordagem acerca do mundo urbano belemense às representações coletivas, como pensadas por Durkheim e Mauss (2005)..$^{16}$

\section{Consideraçóes finais}

Neste artigo procuramos enfatizar que uma "arqueologia da memória" pode revelar que os tempos se sobrepóem e indicam a dinâmica complexa de transformações do mundo urbano e de sua aura. Os fantasmas que habitam as paisagens e circulam soturnos pela noite fazem parte do "espírito do lugar”, constituindo formas sensíveis que revelam a simbólica das paisagens fantásticas de uma cidade situada no norte do Brasil, onde tempos pretéritos se misturam com o contemporâneo, ressituando a memória do lugar e indicando, assim, a densidade temporal de suas camadas.

Devemos levar em conta as especificidades das narrativas contadas pelos taxistas, nas quais se destacam as imagens do deslocamento, exatamente por se tratar de um item fundamental no cotidiano de todos aqueles que transportam passageiros diariamente. $\mathrm{O}$ contato com o outro - o estranho ou o estrangeiro - constitui uma constante na prática laboral desses homens. O medo decorrente da possibilidade de se deparar com uma "visagem" adviria, dessa forma, da própria tensão e da expectativa diante do contato recorrente com o estranho, ora na forma de pessoas, ora manifestando-se como paisagens - um bairro desconhecido, uma rua nunca antes adentrada e, mesmo, um caminho ainda não percorrido.

Entre as narrativas coletadas, muitas apresentavam alguns traços em comum: a fantasmática do feminino, o deslocamento e a questão das frontei- ras simbólicas relativas ao espaço urbano experienciadas pelos profissionais - entre a cidade e o campo; o centro e a periferia, por exemplo. Nota-se a presença de certas (des)continuidades que revelam derivas e fluxos (Hannerz, 1997) no espaço percorrido. Portanto, as visagens aparecem quando, ao se deslocarem na cidade, os taxistas adentram territórios desconhecidos a fim de realizarem uma "corrida" que conduza o cliente ao seu destino. Dessa forma, eles se desterritorializam, percorrendo lugares em que há um nítido contraste urbanístico em relação ao centro da cidade, espaço onde, preferencialmente, atuam como profissionais.

Aqui, a imagem da fronteira está vinculada a certas formas sensíveis pelas quais os sujeitos percebem o entorno. A partir daí fluem por ele, pois a fronteira está relacionada com aquele que se desloca pela cidade e percebe seus limites, criando uma série de referências imagéticas - um mapeamento cuja simbólica revela a dinâmica da cidade -, as quais o auxiliam na sua orientação no espaço.

Ora refletindo sobre as interpretações dos taxistas em relação às suas experiências na cidade, ora sugerindo que um olhar sensível é capaz de desvelar o caráter fantástico da urbe, entendemos que as narrativas circulantes na cidade de Belém indicam, ao seu modo, o contexto turbulento do mundo urbano brasileiro, emergindo a partir de diversas formas sociais que apontam a necessidade das pessoas em apreender e conformar à sua própria experiência as diferentes temporalidades que vibram na cidade.

\section{Notas}

1 Aproximamo-nos da noção de "imaginário urbano" que aparece em Certeau (1994) e das discussões de Durand (1989) sobre o tema do imaginário. A expressão "imaginários urbanos" utilizada por Canclini (1997) e as reflexões de Gravano (2005) também se mostram relevantes para o presente estudo. $\mathrm{O}$ termo belemense é uma categoria nativa utilizada por diversas pessoas na cidade de Belém, concomitantemente com a denominação belenense. Portanto, os dois termos são utilizados para indicar a pessoa originária $\mathrm{da}$ cidade de Belém.

2 Conforme Langdon (2006, p. 167): “A performance é um evento situado num contexto particular, 
construído pelos participantes. Há papéis e maneiras de falar e agir. Performance é um ato de comunicação, mas como categoria distingue-se dos outros atos de fala principalmente por sua função expressiva ou 'poética', seguindo a definição de Jakobson (1960). A função poética ressalta o modo de expressar a mensagem e não o conteúdo da mensagem. Assim como Bakhtin (1968) dirige sua atenção para como o romance é construído, os estudos desta abordagem dirigem seu interesse para como performances são construídas pelos participantes do evento, examinando o evento artístico (a situação de performance) e o ato artístico (a realização do evento por parte do(s) performer(s))".

3 Sobre a prática do deslocamento relacionada com o trabalho etnográfico, ver Clifford (2000) e acerca do ofício dos motoristas de táxi, ver Eduardo Rocha (2004).

4 Comumente, a expressão "baixada" refere-se aos locais de habitação precária e com pouca infraestrutura urbana. $\mathrm{O}$ termo faz referência às áreas alagadiças e inundáveis ocupadas por moradores de baixa renda da urbe, geralmente localizadas na periferia da cidade.

5 A expressão "fazer o Cristo" significa no vocabulário dos motoristas de ônibus realizar a última viagem do dia de trabalho, geralmente, por volta da meia-noite.

6 Conforme demonstram as pesquisas que realizamos com funcionários do local durante o ano de 2008.

7 "Parte de Belém onde os portugueses, sob o comando de Francisco Caldeira Castelo Branco, desembarcaram, construindo um forte de madeira e uma capela. A praça d'armas (pequena e modesta) era defendida por uma Estacada de Madeira, dentro da qual ficaram os primeiros colonizadores civis e militares. Saindo do forte, os colonos abriram um caminho, que chamaram rua do Norte, e foram se aventurando na construção de casas para moradia. Daí surgiu a cidade, chamada posteriormente de Velha, permanecendo esta denominação até os dias presentes. É a parte colonial que resta da Belém dos séculos XVII e XVIII" (Cruz, [1970] 1992, p. 30).

8 Os "senhores da borracha" correspondem à elite econômica beneficiada pela extração e comércio do látex, material extraído da espécie vegetal Haevea brasiliensis e utilizado na produção de objetos de borracha. Sobre o tema, ver Sarges (2002).

9 Em negrito encontram-se os nomes de bairros de Belém; em itálico, os nomes das ruas e locais mencionados na narrativa.

10 Roberto DaMatta (1997, p. 45) afirma acerca dos "espaços transitórios" - em oposição aos "permanentes"
- que "tudo o que está relacionado ao paradoxo, ao conflito ou à contradição - como as regiōes pobres ou meretrício - fica num espaço singular. Geralmente são regiōes periféricas ou escondidas por tapumes. Jamais são concebidas como espaços permanentes ou estruturalmente complementares às áreas mais nobres da mesma cidade, mas sempre vistos como locais de transição: 'zonas', 'brejos', 'mangues' e 'alagados'. Locais liminares, onde a presença conjunta da terra e da água marca um espaço físico confuso e necessariamente ambíguo".

11 Retomamos a narrativa de seu Laranjeiras que aparece em outro artigo de nossa autoria (Soares e Silveira, 2008). No entanto, damos aqui outro enfoque às reflexões acerca de sua narrativa.

12 Lugar em que se situa a Feira da Bandeira Branca, entre os bairros do Marco e do Souza.

13 Universidade da Amazônia.

14 Escreve o literato Dalcídio Jurandir em 1960: "Região de Belém ao lado da qual, no fim do século XIX, foi construído, pelos ingleses, um porto para exportação do látex. Em 1/12/1901, o Ver-o-Peso ganhou o mercado de ferro. Hoje, a região corresponde a um ancoradouro (onde aportam barcos de pesca, que trazem diversos produtos das Ilhas para serem vendidos ali), a uma Feira e ao Mercado de Ferro. Nessa região se comercializam plantas medicinais e 'mágicas', banhos de cheiro, verduras, carnes, peixes, frutos da terra e importados, comida pronta, artesanato. $\mathrm{O}$ nome da região tem sua origem no período colonial, quando na área funcionava a Casa do Haver-do-Peso, onde era pesada a mercadoria vinda do interior, para cobrança de impostos devidos à Coroa Portuguesa” (2004, p. 548).

15 Espaço recreativo onde ocorre o desfile anual das escolas de samba da cidade de Belém durante o Carnaval.

16 A abordagem sociológica do campo das representações coletivas de que nos aproximamos difere daquela de Alba (2004), que refletiu em torno dos mapas mentais (ou cognitivos) entre os habitantes da Cidade do México por meio da psicologia e da abordagem teórica relativa à "perspectiva transacional da relação indívíduo-ambiente" e das representações sociais.

\section{BIBLIOGRAFIA}

ALBA, Martha de. (2004), "Mapas mentales de la Ciudad de México: una aproximación psicosocial al estudio de las representaciones espa- 
ciales". Estúdios Demográficos y Urbanos, 55: $115-143$.

AUGÉ, Marc. (1994), Não-Lugares: introdução a uma antropologia da supermodernidade. Tradução de Maria Lúcia Pereira. $1^{a}$ edição. Campinas, Papirus.

BACHELARD, Gaston. (1991), A terra e os devaneios da vontade: ensaio sobre a imaginação das forças.Tradução de Antonio de Pádua Danesi. $1^{a}$ edição. São Paulo, Martins Fontes.

BACHELARD, Gaston. (2006), A poética do devaneio. Tradução de Antonio de Pádua Danesi. 2. ed. São Paulo, Martins Fontes.

BENJAMIN, Walter. (1994), Obras escolbidas III. Charles Baudelaire: um lírico no ange do capitalismo. Tradução de José Carlos Martins Barbosa e Hemerson Alves Baptista. 3. ed. São Paulo, Brasiliense. (1996), "O narrador: consideraçōes sobre a obra de Nikolai Leskov", in Walter Benjamin, Obras escolhidas. Magia e técnica, arte e politica: ensaios sobre literatura e história da cultura. Tradução de Sérgio Paulo Rouanet. 7. ed. São Paulo, Brasiliense.

CAIAFA, Janice. (2007), Aventura das cidades, Rio de Janeiro, FGV.

CAILLOIS, Roger. (1938), Le mythe et l'homme. Gallimard.

CANCELA, Cristina Donza. (2009), "Paisagens e trajetórias na Belém da economia da borracha”, in F. L. A. da Silveira e C. D. Cancela (orgs.), Paisagem e cultura: dinâmica do patrimônio e da memória na atualidade. $1^{a}$ edição. Belém, EDUFPA.

CANCLINI, Nestor Garcia. (1997), Imaginarios urbanos. Buenos Aires, Editoral Universitaria de Buenos Aires.

CERTEAU, Michel de. (1994), A invenção do cotidiano: artes de fazer. Tradução de Ephraim Ferreira Alves. 5. ed. Rio de Janeiro, Vozes.

(1995), A cultura no plural. Tradução de Enid Abreu Dobránzky. 1ª edição. Campinas, Papirus.

CLIFFORD, James. (2000), "Culturas viajantes", in A. A. Arantes (org.), O espaço da diferença. $1^{a}$ edição. Campinas, Papirus.

CORBIN, Alain. (1989), O território do vazio: a praia e o imaginário ocidental. Tradução de Paulo Neves. $1^{a}$ edição. São Paulo, Companhia das Letras.

CRAPANZANO, Vincent. (1994), "Réflexions sur une anthropologie des émotions". Terrain, 22: 109-117.

CRUZ, Ernesto. (1973), História de Belém. $1^{\text {a }}$ edição. Belém, Editora da UFPA, vol. 2. ([1970] 1992), Ruas de Belém: significado histórico de suas denominaçōes. 2. ed. Belém, Cejup.

DAMATTA, Roberto. (1997), A casa e a rua: espaço, cidadania, mulher e morte no Brasil. Rio de Janeiro, Rocco.

DELUMEAU, Jean. (1996), História do medo no Ocidente, 1300-1800. Tradução de Maria Lúcia Machado. $1^{a}$ edição. São Paulo, Companhia das Letras.

DURAND, Gilbert. (1989), As estruturas antropológicas do imaginário. Tradução de Hélder Godinho. $1^{a}$ ediçãa. Lisboa, Presença.

(1993), A imaginação simbólica. Tradução de Carlos A. de Brito. $1^{a}$ edição. Lisboa, Edições 70.

(1998), O Imaginário: ensaio acerca das ciências e da filosofia da imagem. Tradução de René Eve Levié. 1 1a edição. Rio de Janeiro, Difel.

DURKHEIM, Émile \& MAUSS, Marcel. (2005), "Contribuição para o estudo das representações coletivas" [1903], in M. Mauss, Ensaios de sociologia, São Paulo, Perspectiva, pp. 399-455.

ECKERT, Cornelia \& ROCHA, Ana Luiza Carvalho da. (2005), O tempo e a cidade. $1^{\text {a }}$ edição. Porto Alegre, Editora da UFRGS.

GELL, Alfred. (1985), "How to read a map: remarks on the practical logic of navigation". Man, 20 (2): 271-286.

GRAVANO, Ariel (comp.). (2005), Imaginários sociales de la ciudad media: emblemas, fragmentaciones y otredades urbanas. Estúdios de Antropología Urbana. Buenos Aires, Tandil/Universidad Nacional del Centro de la Província de Buenos Aires.

HANNERZ, Ulf. (1997), "Fluxos, fronteiras, híbridos: palavras chave da antropologia transnacional". Man, 3 (1): 7-39. 
INGOLD, Tim. (2000), The perception of the environment: essays in livelihood, dwelling and skill. Londres/Nova York, Routledge.

JURANDIR, Dalcídio. ([1960] 2004), Belém do Grão-Pará. 2. ed. Belém/Rio de Janeiro, Edufpa/Casa Rui Barbosa.

KAPFERER, Bruce. (1986), "Performance and the structuring of meaning and experience", in $\mathrm{V}$. Turner e E. Bruner (eds), Antropology of experience, Chicago, University of Illinois Press.

LANGDON, Esther J. (2006), "Performance e sua diversidade como paradigma analítico: a contribuição da abordagem de Bauman e Briggs. ILHA, $8(1,2)$ : 162-183.

MAFFESOLI, Michel. (1994), "O poder dos espaços de representação". Tempo Brasileiro, 116: 59-70.

MAUSS, Marcel. (2005), Ensaios de sociologia. 2. ed. São Paulo, Perspectiva.

MONTEIRO, Walcyr. (2005), Visagens e assombraçôes de Belém. 4. ed. Belém, Paka-Tatu.

PARK, Robert E. (1987), "A cidade: sugestões para a investigação do comportamento humano no meio urbano", in O. G. Velho (org.). O fenômeno urbano. 4 ed. Rio de Janeiro, Guanabara.

PESAVENTO, Sandra J. (2002), O imaginário da cidade: visões literárias do urbano - Paris, Rio de Janeiro, Porto Alegre. 2. ed. Porto Alegre, Editora da UFRGS.

RICOEUR, Paul. (1994), Tempo e narrativa. Tradução de Constança Marcondes Cesar. $1^{\text {a }}$ edição. São Paulo, Papirus, vol. 1.

ROCHA, Ana. Luísa Carvalho da. (1994), Le santuaire de désodre: l'art de savoir vivre des tendres barbares sous les Tristes Tropiques. Paris, tese de doutorado, Paris V, Sorbonne. (1995), "A irracionalidade do belo e a estética urbana no Brasil", in Z. Mesquita e C. R. Brandão (orgs.), Territórios do cotidiano: uma introdução a novos olhares e experiências. $1^{\mathrm{a}}$ edição. Porto Alegre/Santa Cruz do Sul, UFRGS/Unisc.

ROCHA, Ana Luísa Carvalho da \& ECKERT, Cornelia. (2000), "Os jogos da memória". ILHA, 1 (2): 71-84.

ROCHA, Eduardo C. (2004), Estranhos encontros: aproximação etnográfica do táxi, sistema de transporte individual de passageiros. Monografia (Bacharelado em Antropologia). Brasília, Universidade Nacional de Brasília, Departamento de Antropologia.

SANSOT, Pierre. (1986), Les formes sensibles de la vie sociale. Paris, PUF.

SARGES, Maria de Nazaré. (2002), Belém: riquezas produzindo a Belle-Époque (1870-1912). 1a edição. Belém, Paka-Tatu.

SCHMITT, Jean-Claude. (1999), Os vivos e os mortos na sociedade medieval. Tradução de Maria Lúcia Machado. $1^{a}$ edição. São Paulo, Companhia das Letras.

SILVEIRA, Flávio Leonel Abreu da. (2008) "Belém fantástica, Belém da memória”, in J. F. Beltrão e A. O. Vieira Jr. (org.), Conheça Belém, Co-memore o Pará. $1^{\text {a }}$ edição. Belém, EDUFPA.

SOARES, Pedro \& SILVEIRA, Flávio. L. A. (2008), "Cidade em movimento: os taxistas como guardiōes da memória em Belém (PA)”. Amazônia: Ci. \& Desenv., 4 (7).

TRIGG, Dylan. (2010), "Architeture and nostalgia in the age of ruin". Disponível em <http://sussex.academia.edu/DylanTrigg/Papers/134941/ Architecture-and-Nostalgia-in-the-Age-of-Ruin>.

TUAN, Yi-Fu. (2006), Paisagens do medo. Tradução de Lívia de Oliveira. $1^{a}$ edição. São Paulo, Unesp.

VELHO, Gilberto. (1994), Projeto e metamorfose: antropologia das sociedades complexas. $1^{\text {a }}$ edição. Rio de Janeiro, Jorge Zahar. 


\section{AS PAISAGENS FANTÁSTICAS NUMA CIDADE AMAZÔNICA SOB O OLHAR DOS TAXISTAS}

\section{Flávio Leonel Abreu da Silveira e Pedro Paulo de Miranda Araújo Soares}

Palavras-chave: Antropologia urbana; Memória; Imaginário; Narrativas; Taxistas.

Este artigo tem como objetivo analisar as impressões e as interpretações de antigos taxistas a respeito das mudanças ocorridas na cidade de Belém no decorrer do século XX. Nesse contexto, os motoristas autônomos de Belém figuram como portadores de um conhecimento sobre a cidade baseado na prática do deslocamento, revelando uma memória coletiva ligada aos processos de urbanização e transformação do viver na capital paraense. Emerge, então, um imaginário construído a respeito da cidade de Belém no interior de uma categoria profissional específica, bem como representações, aspirações, devaneios e queixas comuns sobre o viver na cidade. Assim, os pontos de vista desses profissionais sobre Belém aparecem expressos em narrativas fantásticas em que os taxistas encontram visagens e assombrações durante sua jornada de trabalho.

\section{THE FANTASTIC LANDSCAPES IN AN AMAZON TOWN THROUGH THE TAXI-DRIVER'S PERSPECTIVE}

\section{Flávio Leonel Abreu da Silveira and Pedro Paulo de Miranda Araújo Soares}

Keywords: Urban anthropology; Memory; Imaginary; Narratives; Taxi-drivers.

This article intends to analyze the taxidriver's impressions and interpretations about the changes that have been taken place in the city of Belém throughout the XXth century. Hence, the taxi-drivers of Belém appear as owners of a knowledge concerning the town based in the practice of getting around an urban area, revealing a collective memory connected to the process of changing of the town's landscape. So, an imaginary emerges built inside a professional category in relation to the city of Belém, as well as representations, ideas, imaginings and complaints involving the life in town. Therefore, the taxi-driver's points of view about Belém are exposed when they tell their narratives of supernatural meetings with ghosts and haunting.

\section{LES PAYSAGES FANTASTIQUES DANS UNE VILLE D'AMAZONIE D'APRÈS LE REGARD DES CHAUFFEURS DE TAXI}

\section{Flávio Leonel Abreu da Silveira et Pedro Paulo de Miranda Araújo Soares}

Mots-clés: Anthropologie urbaine; Mémoire; Imaginaire; Narratives; Chauffeurs de taxi.

Cet article a pour objectif d'analyser les impressions et les interprétations d'anciens chauffeurs de taxi à propos des changements qui ont eu lieu dans la ville de Belém au cours du XXe siècle. Dans ce contexte, ces chauffeurs autonomes de Belém possèdent une connaissance de la ville qui a pour base la pratique du déplacement et révèle une mémoire collective liée aux processus d'urbanisation et de transformation de la vie quotidienne dans la capitale du Pará. C'est ainsi qu'émerge, à l'intérieur d'une catégorie professionnelle spécifique, un imaginaire construit à propos de la ville de Belém et des représentations, des aspirations, des rêveries et des mécontentements communs sur la vie au quotidien dans la ville. Les points de vue de ces professionnels sur Belém s'expriment dans les récits fantastiques où les chauffeurs de taxi se retrouvent face à des fantômes et des apparitions pendant leurs journées de travail.

Errata: o nome do primeiro autor do texto foi corrigido de Flávio Leonel para Flávio Leonel Abreu da Silveira. 